\title{
Ride Comfort Control System Considering Physiological and Psychological Characteristics: Effect of Masking on Vertical Vibration on Passengers
}

\author{
Keigo Ikeda ${ }^{1}$, Ayato Endo ${ }^{1}$, Ryosuke Minowa ${ }^{1}$, Takayoshi Narita ${ }^{2}$ and Hideaki Kato ${ }^{2, *}$ \\ 1 Course of Mechanical Engineering, Tokai University, Kitakaname 4-4-1, Hiratsuka-shi 259-1292, Japan; \\ 7bemm009@mail.u-tokai.ac.jp (K.I.); 6lemm001@mail.u-tokai.ac.jp (A.E.); \\ 8bemm078@mail.u-tokai.ac.jp (R.M.) \\ 2 Department of Prime Mover Engineering, Tokai University, Kitakaname 4-4-1, Hiratsuka-shi 259-1292, Japan; \\ narita@tsc.u-tokai.ac.jp \\ * Correspondence: hkato@tokai-u.jp; Tel.: +81-463-58-1211
}

Received: 15 June 2018; Accepted: 20 July 2018; Published: 23 July 2018

\begin{abstract}
Active seat suspension has been proposed to improve ride comfort for ultra-compact mobility. Regarding the ride comfort of passengers due to vertical vibration, the authors have confirmed from biometry measurements that reduction of the vibration acceleration does not always produce the best ride comfort for passengers. Therefore, heart rate variability that can quantitatively reflect stress is measured in real time, and a control method was proposed that feeds back to active suspension and confirms its effectiveness by fundamental verification. In this paper, we will confirm the influence of the vibration stress on the psychological state of the occupant by the masking method.
\end{abstract}

Keywords: voice coil motor; active seat suspension; electrocardiogram

\section{Introduction}

Because the demand for advanced product design in transportation machines such as automobiles, railways, and aircraft is increasing, there is a strong desire to improve quality from the psychological point of view of a passenger, such as mental stress and physical ride comfort. Degradation of ride comfort in transport machines has various influences such as vibration, noise, and ambient temperature, but there are also survey results which show that vibration affects comfort, especially in trains [1].

In addition to improving ride comfort against vibrations in automobiles, evaluation of comfort using the response characteristics of the human body to vibration [2,3], grasp of psychological effects by sensory evaluation [4], quantification of psychology, and fatigue state using physiological measurement, a study on the establishment of a vibration mitigation method is proposed [5].

Against this backdrop, the authors focus on the vibration of ultra-compact mobility vehicles, which have attracted attention as a result of the deterioration of ride comfort as a major issue. Although it has been widespread in recent years, we continue to study the countermeasures from several viewpoints. First, for ultra-small vehicles characterized by a compact and lightweight body, a voice coil motor is placed at the bottom of the seat with an active seat suspension that only controls the occupants, not the entire vehicle. Although it is technically difficult to install an actuator in a limited space and to exhibit high thrust, it is possible to obtain reasonable control [6]. In addition, we investigated a control method that can obtain a high vibration damping performance even when occupants of different weights occupy the vehicle, such as during car sharing, and have demonstrated its usefulness experimentally [7]. Conversely, in order to quantitatively and continuously evaluate the psychological state of an occupant, a system is proposed in which physiological measurement and vibration control 
are performed in real time [8]. In the early stages of control system construction, the psychological state was evaluated by physiological measurement of the autonomic nervous system activity index calculated from heart rate variability and fed back in real time, and by switching the vibration control according to the psychological state of the occupant, results were continuously improved. To improve comfort for vibrations, we compare not only the conventional vibration characteristics of the human body, but also psychological characteristics based on physiological measurement.

Physiologic measurement devices can be obtained easily, so they have made remarkable progress in recent years. However, a system that constantly controls, measures, evaluates, and reflects the heart rate during vehicle operation may be a burden on the driver. Therefore, it is necessary to determine the psychological and physical characteristics of each passenger in advance. Thus, construction of a ride comfort control system (Figure 1) that automatically selects vibration control is desired. That is, it is necessary to determine the psychological characteristics of the occupant for various vibrations in advance to construct a system that provides vibration control. The simple evaluation of psychological characteristics for vibration has already been studied by the authors. Previous experiments confirm that vibration frequency affects psychological characteristics [9]. Furthermore, we evaluated the influence of control to reduce vibration acceleration on psychological characteristics, and it has been confirmed that continuing to apply only the control system that reduces the acceleration amplitude of vibrations having uncomfortable frequency characteristics does not always psychologically improve ride comfort [10]. Therefore, to improve ride comfort, it is necessary to construct a new vibration control method according to psychological characteristics.

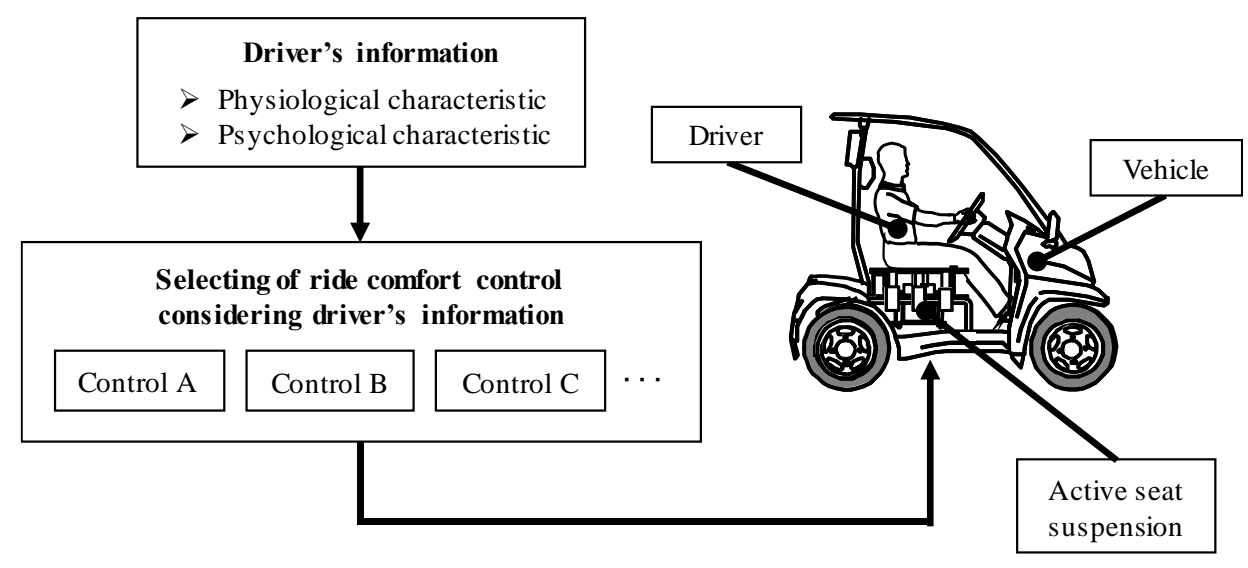

Figure 1. Ride comfort control system.

In the case of using this system for a vibration control system, the performance of the actuator is limited in terms of stroke, thrust, response frequency, etc. An inexpensive actuator which cannot secure a sufficient response and thrust at the next stage of popularization was used. When a vibration that is psychologically uncomfortable is input as a disturbance, reduction of this disturbance is being studied from various viewpoints, as described above. If it is possible to establish a method to change the comfort of the ride by aggressively superimposing the vibrations of a frequency band different from the inputted disturbance to adjust the driving environment, making it more comfortable for passengers, it will be possible to propose an innovative ride comfort improvement method. In this study, we propose a method of masking which relatively reduces the sensitivity of undesirable vibrations by aggressively inputting vibrations of other frequencies against the vibration of frequencies which is input as disturbance and is perceived as discomfort. Conversely, though the evaluation of physical characteristics and comfort by sensory evaluation has been performed on composite vibration obtained [11] by superimposing a plurality of vibrations having different frequency characteristics, evaluation of psychological characteristics based on physiological measurement has not been performed; it is necessary to verify this experimentally. 
Based on the above contents, in this paper, as a fundamental study on masking, we verified its effect using the Vibration Test by simulating the vibration environment applying the masking. Experiments on vibration with sinusoidal vibration with single frequency characteristics were first conducted, and the vibration used for masking was investigated. Next, we simulated the situation masked by using the frequency selected by this experiment and carried out the vibration test with a small number of subjects. At this time, the relative acceleration amplitude of the vibration to be superimposed on the disturbance was also examined. In addition, we carried out a demonstration experiment by increasing the number of subjects further using a condition that improves ride comfort, which was confirmed by a small number of subjects. From these investigations, we clarify the influence of masking in vertical vibration on the comfort of riders and present the prospects for the design of a new ride comfort control system.

\section{Masking Method}

In this paper, we propose a masking method as a new type of vibration control for improving the ride comfort of vehicles. Figure 2 shows schematic drawings of the masking method. The masking method is a type of vibration control considering the vibration frequency sensation of a human. The purpose of general vibration control is the elimination of unpleasant disturbance. However, the masking method decreases the sensitivity of disturbance by means of superimposing vibration. It is advantageous in that it is available even though the disturbance is unknown or complicated.

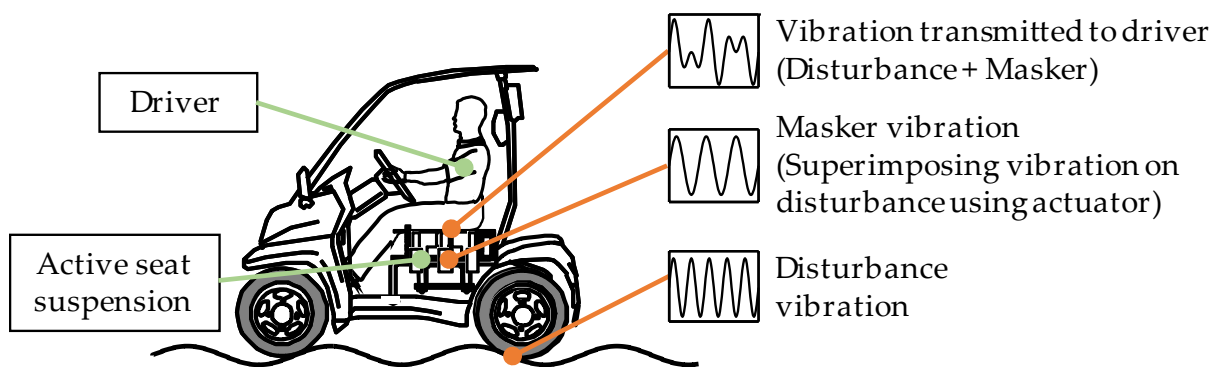

Figure 2. Masking method.

\section{Evaluation of Psychological State Using Heart Rate Variability}

In this study, an electrocardiogram (ECG) which can perform a simple measurement and can continuously acquire data was used as a physiological measurement for evaluating the psychological stress of the participant. The ECG represents the electrical activity of the heart and measures the potential difference in heart rate via an electrode directly attached to the chest. Figure 3 shows an example of an electrocardiogram waveform obtained during measurement. In the same figure, the peak in the positive direction appearing periodically is called an $\mathrm{R}$ wave and reflects contraction of the left ventricle. The time from the $\mathrm{R}$ wave to the next $\mathrm{R}$ wave is called the $\mathrm{R}$ to $\mathrm{R}$ interval (RRI). When this RRI is organized as a time history, it becomes as shown in Figure 4. Further, frequency analysis is performed on RRI time history to calculate the power spectral density, as shown in Figure 5. The integrated value in the range of 0.04 to $0.15 \mathrm{~Hz}$ with this power spectral density is referred to as low frequency (LF), and the integral value in the range of 0.15 to $0.4 \mathrm{~Hz}$ is referred to as high frequency (HF). LF and HF are widely used as indicators of activities of the autonomic, sympathetic, and parasympathetic nervous systems. In this paper, a comparison of acquired data is simple, and therefore autonomic nervous system activity of the occupant under the experiment was evaluated by LF/HF, which is an indicator of the activity state of the sympathetic and parasympathetic nervous system. It is considered that there is a psychological state affected by the autonomic nervous system activity; $\mathrm{LF} / \mathrm{HF}$ is predominant in the sympathetic nervous system - if the value is high, the parasympathetic nervous system dominates. If it is low, it can be evaluated as a relaxed state. 


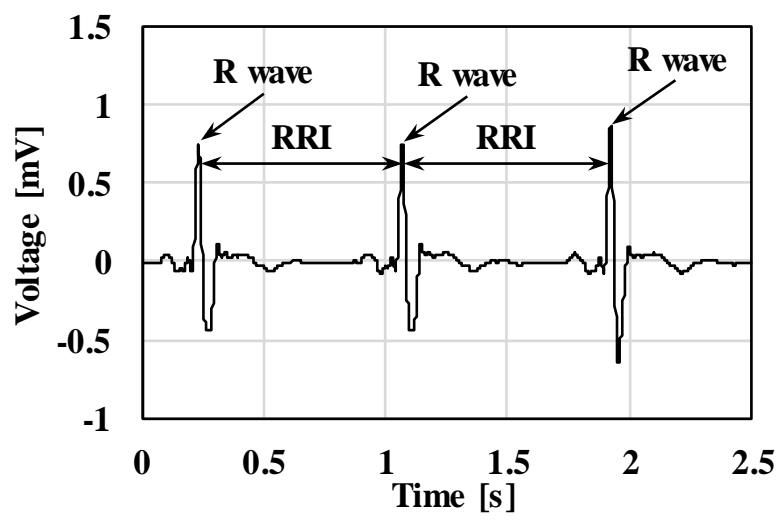

Figure 3. Electrocardiogram (ECG).

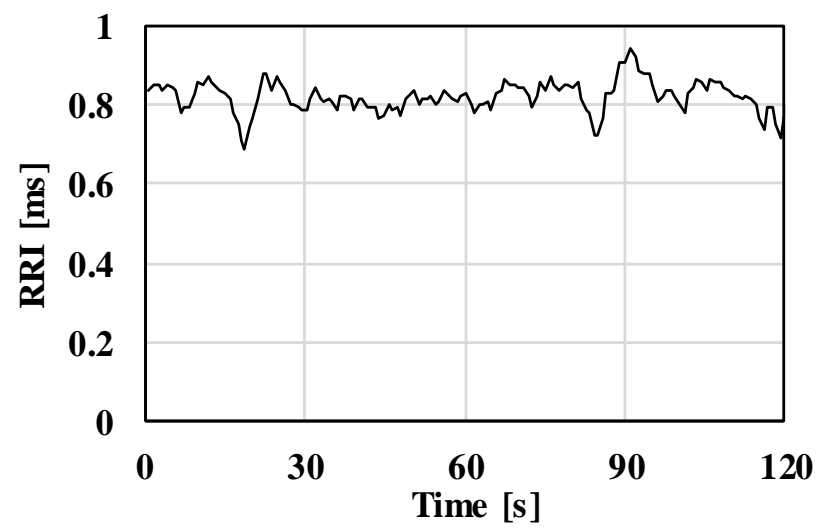

Figure 4. Time history of the R-R interval (RRI).

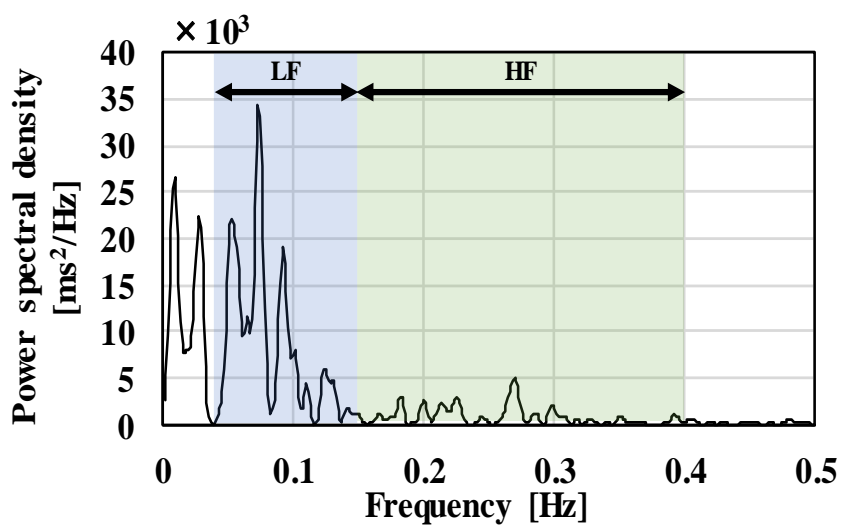

Figure 5. Frequency analysis of RRI time history.

\section{Experimental Apparatus and Method}

\subsection{Active Seat Suspension}

In this study, in order to confirm the change of riding comfort by masking, the vibration was carried out using an ultra-compact mobility vehicle (Figure 6) where the active seat suspension (Figure 7) was installed as the experimental vehicle. In the active seat suspension, aluminum plates are used for the seat portion, and when not driving, the subject is supported by four coil springs. The movement direction of the seat is restrained by the four linear sliders installed in the surroundings in the vertical direction. For the control actuator, a voice coil motor, which is a type of linear motor that can be highly 
responsive to thrust, was adopted. In this experiment, since the vibration test is performed using active seat suspension, there is a possibility that vibration different from the objective may be input in the state when the vehicle is parked. For this reason, we conducted an experiment with the vehicle jacked up. Furthermore, to prevent the psychological state from changing due to influences other than vibration, it was carried out in a state of the vehicle parked indoors.
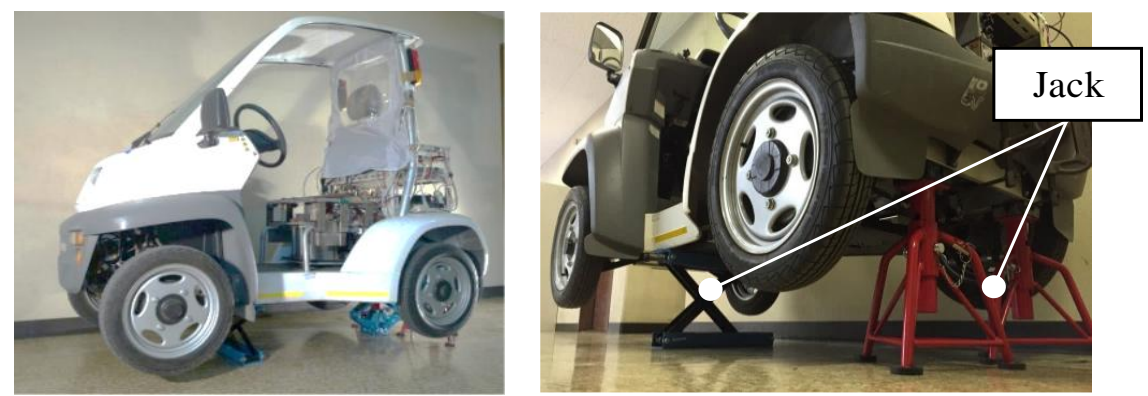

Figure 6. Photograph of the ultra-compact vehicle.

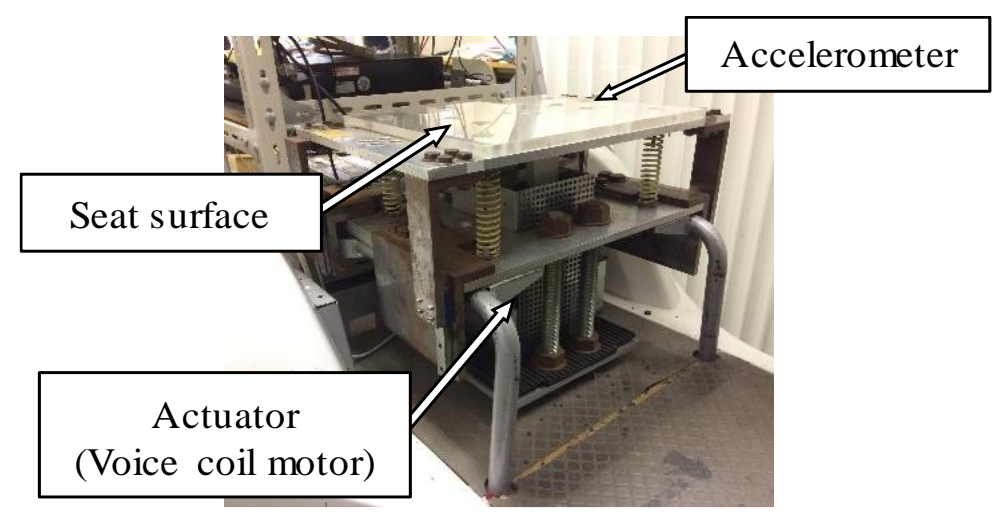

Figure 7. Photograph of active seat suspension.

In this experiment, the subject was seated on the active seat suspension, and vibration was applied to the subject by only actuating the seat. In order to verify the effect of masking, the loaded vibrations set several vibrations with different frequency characteristics, and the details are described in each chapter. Also, to make the posture of the subject closer to the actual driving environment, subjects were directed to grasp the steering wheel and assume a driving posture. This is because the vibration characteristics of the human body change depending on the posture when exposed to vibration, as shown by Mansfield et al. [12].

\subsection{Measuring Device and Method of Electrocardiogram}

Bio Amp ML132, Power Lab 8/35 PL 3508, MLA 2340, and MLA 2503 shield leads (AD Instruments, Sydney, Australia) were used for ECG measurement, and the heart rate variability of the company was used as the analysis system. The method of affixing the electrode is not easily affected by action potentials other than myocardial activity, and NASA induction that can be measured stably was adopted. In addition, since the ECG makes it difficult to accurately estimate the autonomic nervous system activity by changing the breathing rhythm, we directed subjects not to speak during measurement.

\subsection{Experimental Method}

Figure 8 shows the flow of each vibration experiment. In the vibration test, first, a mental calculation task was given to the subject for one minute, and then the subject was made to ride the vibrating vehicle for three minutes. The ECG was acquired for a total of four minutes. The mental 
calculation task was carried out with the object of matching the psychological state of each experiment by loading the subject with a certain stress before the experiment. The subject was instructed to add two types of numerical values (two digits) intermittently displayed on the monitor installed in front of the vehicle for five seconds each. At this time, subjects were also instructed not to answer the calculations aloud because the influence on the heart rate variation by the utterance was a concern. In the vibration experiment, in order to reproduce the actual driving state, we directed the subjects to watch the monitor in the driving direction with the driving attitude (Figure 9). Considering the fatigue and physical and psychological burden on the subject by the vibration test, we set a sufficient break time between experiments in each vehicle. Blood pressure and heart rate were measured before starting the experiment in each vehicle, and it was confirmed that the values were nearly constant, so that the psychological state of the subjects before the vibration experiment was approximately the same. Regarding this experiment, it was approved by the ethics committee of Tokai University's "Research targeted at humans", and the subjects were given prior explanation of the contents of the experiment. Subjects agreeing on cooperation with the experiment signed and sealed the consent form approved by the committee.

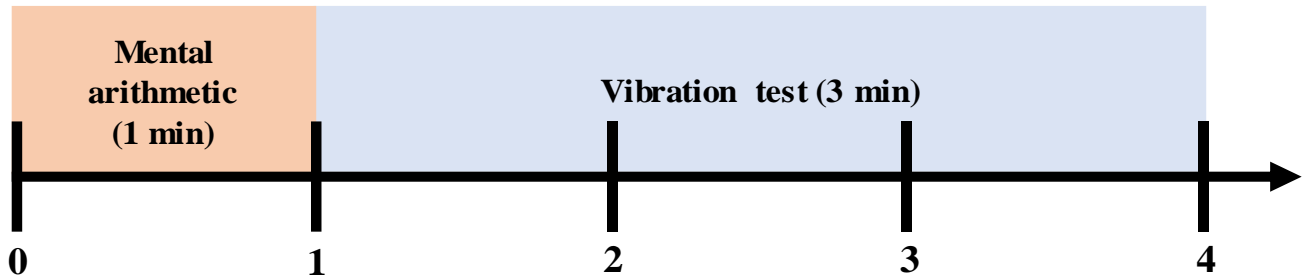

Figure 8. Flow of the experiments.

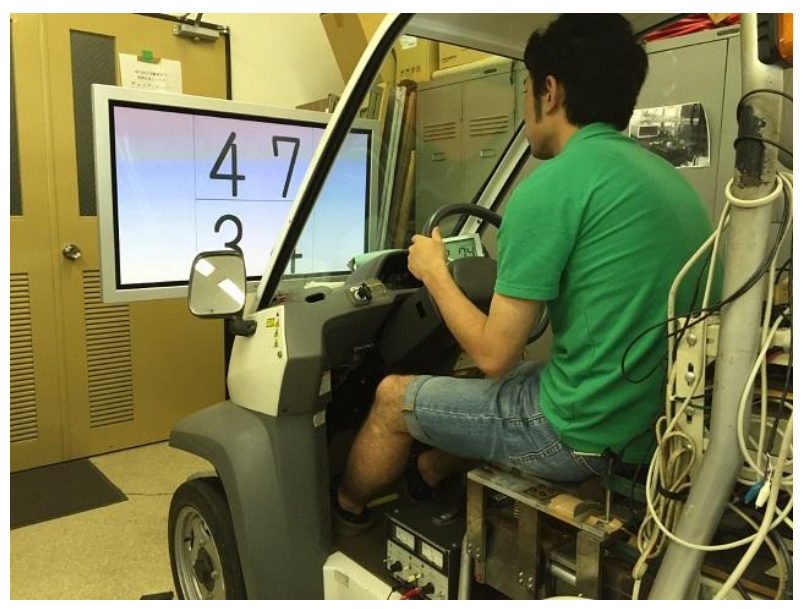

Figure 9. Photograph of the experiment set up.

\section{Vibration Experiment of Single Frequency with Constant Acceleration Amplitude}

\subsection{Vibration Condition}

In this section, to investigate the vibration frequency applied to the masking, which is the vibration control which superimposes the vibrations of multiple frequencies, a vibration experiment with a single frequency sinusoidal wave was performed as a basic experiment. The authors have already reported that the change in the LF/HF occurs depending on the frequency when the displacement amplitude is constant, but in the ride comfort assessment for vibration, in general, since the acceleration is used, the vibration condition with a constant acceleration amplitude was chosen. We decided to measure the psychological state of the subjects. 
For sensory curves of ISO 2631 [13] and ride comfort limit curves of Janeway [14], it is said to be an unpleasant vibration as humans feel vibration sensitively at a 4 to $8 \mathrm{~Hz}$ vibration frequency. In addition, when steady vibration was input by Takei et al. [15], it was demonstrated that subjects could express a feeling for vibration with a fluffy feeling at 0.2 to $3 \mathrm{~Hz}$ and a feeling of fluttering at 8 to $20 \mathrm{~Hz}$. Therefore, we investigated this by adding $3 \mathrm{~Hz}, 9 \mathrm{~Hz}$, and $10 \mathrm{~Hz}$, which differ in the sense of vibration from oscillation frequency 4 to $8 \mathrm{~Hz}$ which is unpleasant, with vibration at a single frequency of 3 to $10 \mathrm{~Hz}$. Acceleration amplitude was set to $1.5 \mathrm{~m} / \mathrm{s}^{2}$ under all conditions, taking into consideration the worst vibration input assumed to be a steady input during driving and the performance of the actuator. The notation of amplitude in this paper indicates a single amplitude value. In this chapter, since the objective is to determine changes in psychological state by LF/HF, the subject was a male university student (age 22 years old).

\subsection{Experimental Result}

Figure 10 shows the LF/HF calculated from the ECG data during the vibration time at each frequency. From the figure, it can be confirmed that a change appears in LF/HF, which is a stress index according to frequency. As described above, LF/HF can be evaluated as being in a higher stress state as the value becomes higher. It can be confirmed that the subject was most stressed at $7 \mathrm{~Hz}$. It was confirmed that there was approximately a two-fold difference at the highest value of $7 \mathrm{~Hz}$ compared to $3 \mathrm{~Hz}$, which has the lowest LF/HF. In addition, $3 \mathrm{~Hz}$ (fluffy feeling) and $10 \mathrm{~Hz}$ (feeling of fluttering) decrease $\mathrm{LF} / \mathrm{HF}$ compared to 4 to $8 \mathrm{~Hz}$ required to improve ride comfort. It suggests that subject was relaxed by 3 and $10 \mathrm{~Hz}$ vibration. From the results obtained in this chapter, it was possible to determine by the LF/HF the psychological state changed according to the vibration frequency in the vertical direction. Based on this result, we will study the influence of masking, combining multiple vibration frequencies on psychological state, in the next chapter.

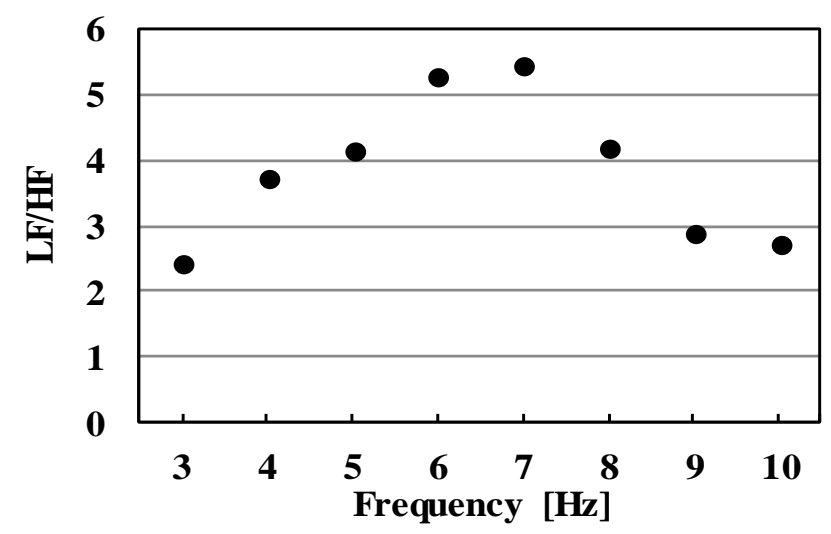

Figure 10. $\mathrm{LF} / \mathrm{HF}$ values in each vibration frequency (amplitude: $1.5 \mathrm{~m} / \mathrm{s}^{2}$ ).

\section{Fundamental Study on Superimposed Vibration}

\subsection{Vibration Condition}

Based on the results in Section 5, this chapter confirms what psychological change is caused in passengers by overlapping vibrations having different frequency characteristics. When masking control is applied when traveling on an actual road, various patterns such as frequency, amplitude, and phase are generated between the vibration input from the road surface and the vibration generated by the actuator. In addition, there are few driving environments in which vibration with a single frequency occurs. At the time of this experiment, there was no report on the influence on the mental state by the superimposition of vibration to date. We conducted a simple vibration experiment simulating the driving environment with the goal of confirming whether masking improves ride comfort as acquiring the basic data. In this study, we assumed single frequency vibration assuming the worst driving 
environment for the vibration characteristics of the human body as a disturbance, so we confirmed the change in the psychological state when masking with a single frequency vibration against the disturbance vibration.

In this experiment, a sinusoidal wave of $5 \mathrm{~Hz}$ was set as the vibration input to the vehicle as a disturbance. This is because Matsumoto et al. [16] reported that the natural frequency of the human body at the sitting position is $5 \mathrm{~Hz}$, and it is considered to be the vibration which should reduce sensitivity most when traveling. The vibration to be superimposed on the disturbance does not affect the human body, and it is necessary to set a vibration which can obtain a different feeling from the disturbance. In this experiment, as explained in Section 5, the two types of vibration frequency bands having different feelings, and two levels of sinusoidal vibrations of 3 and $10 \mathrm{~Hz}$, which produced a minor influence on the ride comfort in the vibration experiment with a single frequency, were used for masking. In addition, since the vibration used for masking is considered to affect the vibration sensed by a relative acceleration amplitude with respect to external disturbance, two types of acceleration amplitude condition with an amplitude of 1.5 and $3.0 \mathrm{~m} / \mathrm{s}^{2}$ are set for each frequency. Table 1 shows the vibration conditions set in this experiment. Additionally, the acceleration response and frequency characteristics in each experimental condition are shown in Figure 11. In addition, these waveforms were calculated by MATLAB. Regarding the phase, when preparing several patterns preliminarily and performing experiments with several subjects, we used the condition that answers that the feeling of riding most changed by masking was obtained.

Table 1. Vibration conditions in experiments.

\begin{tabular}{|c|c|c|c|c|}
\hline \multirow{2}{*}{ Case } & \multicolumn{2}{|c|}{ Vibration 1 (Disturbance) } & \multicolumn{2}{|c|}{ Vibration 2 (Masker) } \\
\hline & Frequency (Hz) & Amplitude $\left(\mathrm{m} / \mathrm{s}^{2}\right)$ & Frequency $(\mathrm{Hz})$ & Amplitude (m/ $\left.\mathrm{s}^{2}\right)$ \\
\hline I & \multirow{3}{*}{5} & \multirow{3}{*}{1.5} & - & - \\
\hline $\begin{array}{c}\text { II } \\
\text { III }\end{array}$ & & & 3 & $\begin{array}{l}1.5 \\
3.0\end{array}$ \\
\hline $\begin{array}{l}\text { IV } \\
\text { V }\end{array}$ & & & 10 & $\begin{array}{l}1.5 \\
3.0\end{array}$ \\
\hline
\end{tabular}
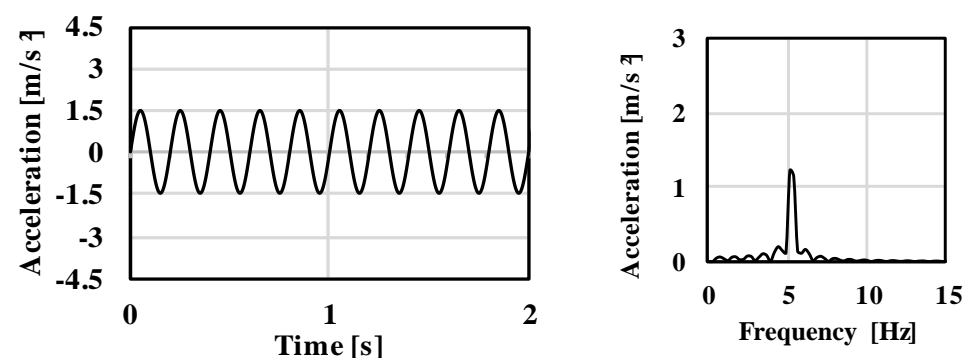

(I)
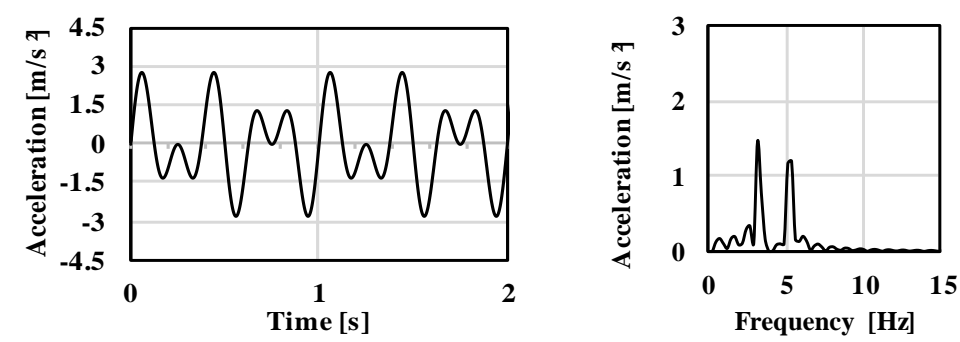

(II)

Figure 11. Cont. 

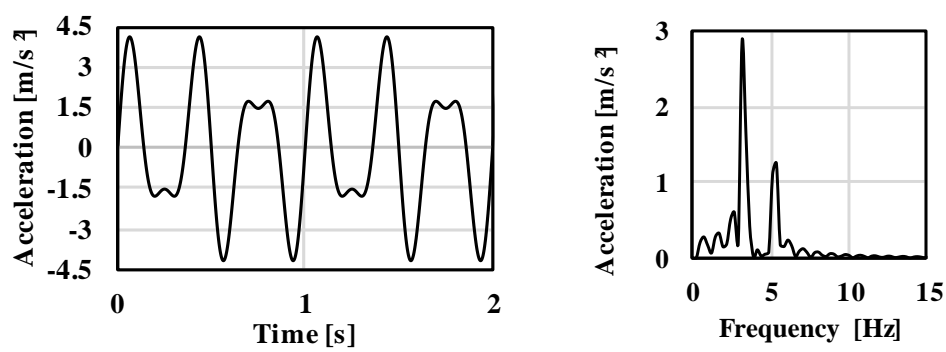

(III)
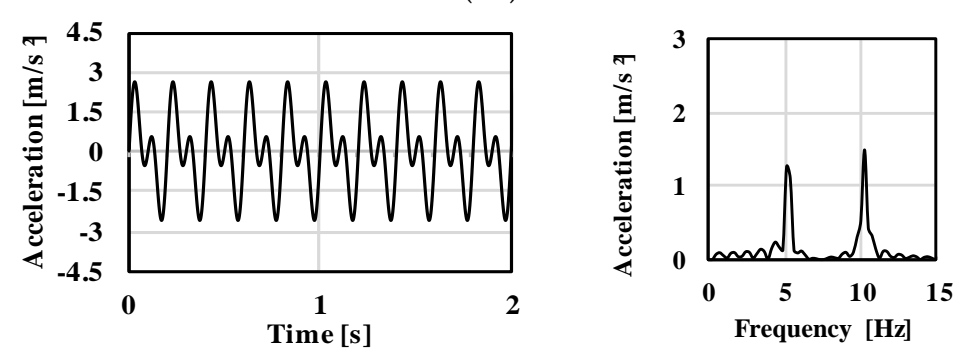

(IV)
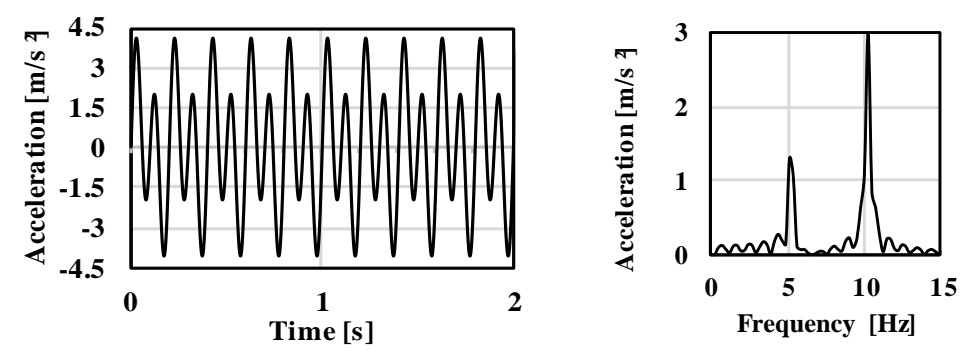

$(\mathbf{V})$

Figure 11. Time histories and spectra on each vibration condition of masking. (I) $5 \mathrm{~Hz}$ (amplitude: $\left.1.5 \mathrm{~m} / \mathrm{s}^{2}\right)$; (II) $5 \mathrm{~Hz}\left(1.5 \mathrm{~m} / \mathrm{s}^{2}\right)+3 \mathrm{~Hz}\left(1.5 \mathrm{~m} / \mathrm{s}^{2}\right)$; (III) $5 \mathrm{~Hz}\left(1.5 \mathrm{~m} / \mathrm{s}^{2}\right)+3 \mathrm{~Hz}\left(3 \mathrm{~m} / \mathrm{s}^{2}\right)$; (IV) $5 \mathrm{~Hz}$ $\left(1.5 \mathrm{~m} / \mathrm{s}^{2}\right)+10 \mathrm{~Hz}\left(1.5 \mathrm{~m} / \mathrm{s}^{2}\right) ;(\mathbf{V}) 5 \mathrm{~Hz}\left(1.5 \mathrm{~m} / \mathrm{s}^{2}\right)+10 \mathrm{~Hz}\left(3 \mathrm{~m} / \mathrm{s}^{2}\right)$.

\subsection{Experimental Result}

The LF/HF in each condition when LF/HF at the reference $5 \mathrm{~Hz}$ amplitude is set to 1 is shown in Figure 12. In addition, the subject in the experiment conducted in Section 5 is subject $C$ in this figure. When the amplitude of the vibration to be superimposed is $1.5 \mathrm{~m} / \mathrm{s}^{2}$, the LF/HF became higher than the disturbance for subject $A$ and $B$. Subject $C$ only became stressed when the superimposed vibration is $10 \mathrm{~Hz}$ and $1.5 \mathrm{~m} / \mathrm{s}^{2}$. From this, it was confirmed that when masking with the same amplitude as the disturbance, the subject becomes stressed.

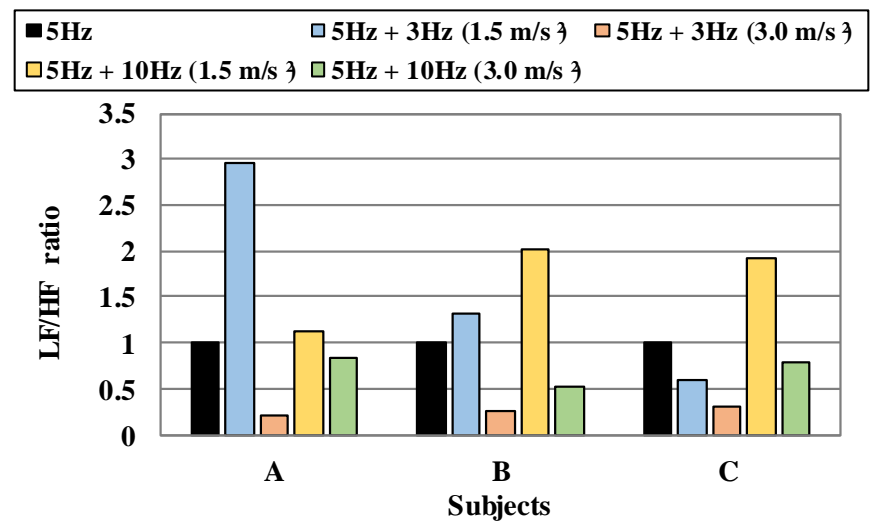

Figure 12. LF/HF values in masking of vibration. 
Conversely, when the acceleration amplitude of the vibration used for masking was twice the disturbance, LF/HF showed a low value compared to the case where three subjects were exposed to the disturbance alone and showed a relaxed state. In the ride comfort evaluation conventionally indicated by ISO, the comfort will be impaired as the amplitude increases, but we confirmed that it is possible to mask unpleasant vibrations by superimposing other vibrations in consideration of frequency. Based on this result, we will increase the number of subjects in the next section and conduct a more detailed verification.

\section{Examination of Ride Comfort Improvement Effect by Masking}

\subsection{Experimental Conditions}

In Section 6, by masking with a vibration of $3 \mathrm{~Hz}$ and $10 \mathrm{~Hz}$ and the amplitude of $3.0 \mathrm{~m} / \mathrm{s}^{2}$ which is twice the amplitude for input disturbance of $5 \mathrm{~Hz}$, three subjects confirmed that they experienced a relaxed state. In this chapter, we recorded results from the three subjects in Section 6 in order to verify the effect and the cause of the masking only condition, which superimposes twice the amplitude at a $3 \mathrm{~Hz}$ and $10 \mathrm{~Hz}$ frequency against $5 \mathrm{~Hz}$ disturbance. We conducted an experiment with 12 subjects. (Male university and graduate students, average age 22.1 years old).

\subsection{Experimental Result}

Figure 13 shows the ratio of LF/HF under each condition with LF/HF set at 1 at a $5 \mathrm{~Hz}$ vibration frequency. Figure 13a shows subjects who were relaxed by masking (subject A, B, C, D, E, and F), and Figure 13 b shows those who classified themselves as stressed by masking (subject $G, H, I, J, K$, and L). In addition, subjects I and L who became stressed by masking became relaxed only when superimposing a vibration of frequency $10 \mathrm{~Hz}$. For these reasons, riding comfort may be improved by masking, and depending on occupants, ride comfort may be different depending on the occasion; we confirmed that experiencing a relaxed ride varies by individual. In addition, when the acceleration amplitude is constant, the displacement amplitude becomes larger at $3 \mathrm{~Hz}$ than $10 \mathrm{~Hz}$. In this experiment, all subject groups who relaxed by masking were relaxed at $3 \mathrm{~Hz}$, so displacement may affect ride comfort.

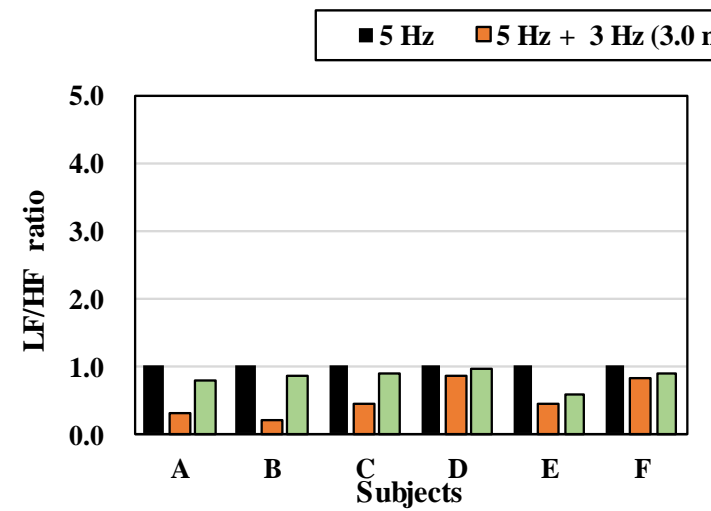

(a)

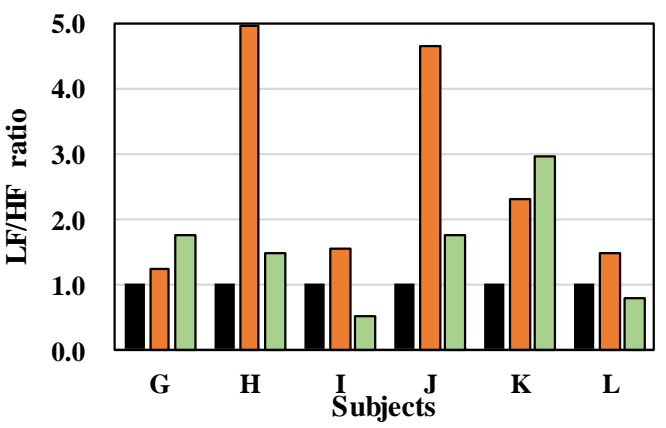

(b)

Figure 13. Comparison of subjects by LF/HF values on masking of vibration: (a) Subjects of becoming relaxed by masking; (b) subjects of becoming stressed by masking.

In order to further pursue the differences in vibration sensation by subjects, the vibration transmission rate to each part of the human body was measured, and an evaluation was made as to whether or not the cause of vibratory sensation differs depending on subjects. Here, the seat surface was vibrated with white noise using the active seat suspension, and the transfer function was calculated from the seat surface acceleration measured, as well as the acceleration of each part of the human body. Incidentally, the acceleration of the human body was measured at five positions, 
including the head, shoulder, arm, waist, and thigh. Figure 14 shows the measurement position of the acceleration. At the time of measurement, the acceleration lead was affixed directly to the skin. Subject A was relaxed by masking, and subject $G$ was stressed by masking. Table 2 shows the highest value of transfer function and frequency of each part of the human body in this experiment.

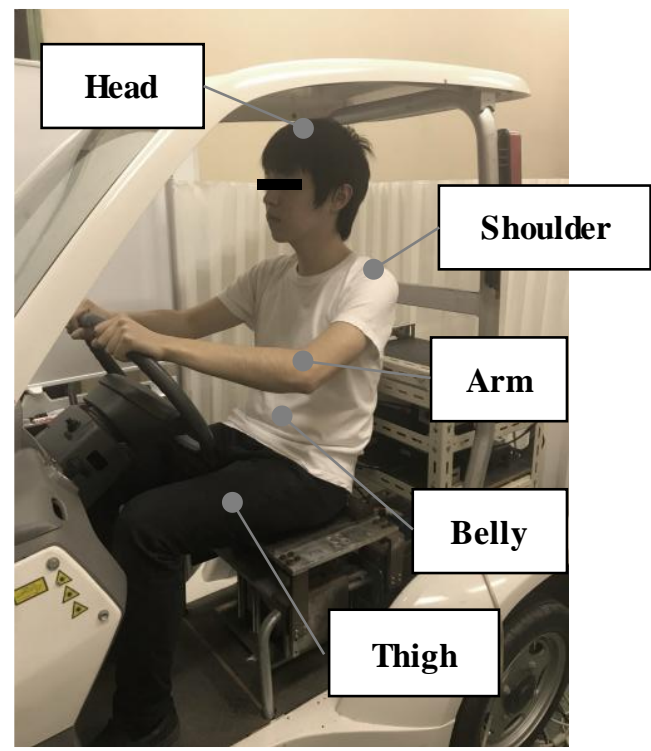

Figure 14. Measuring points of acceleration.

Table 2. Peak of the transfer function in each part of the human body.

\begin{tabular}{ccccccc}
\hline \multirow{2}{*}{ Subjects } & \multicolumn{5}{c}{ Measurement Points } \\
\cline { 3 - 7 } & & Head & Shoulder & Arm & Belly & Thigh \\
\hline \multirow{2}{*}{$\mathrm{A}$} & Frequency $(\mathrm{Hz})$ & 3.0 & 6.0 & 5.5 & 5.5 & 12.5 \\
& Transmissibility $\left(\left(\mathrm{m} / \mathrm{s}^{2}\right) /\left(\mathrm{m} / \mathrm{s}^{2}\right)\right)$ & 2.1 & 4.2 & 3.1 & 2.2 & 2.2 \\
\hline \multirow{2}{*}{$\mathrm{G}$} & Frequency $(\mathrm{Hz})$ & 3.0 & 5.0 & 5.5 & 5.5 & 13.0 \\
& Transmissibility $\left(\left(\mathrm{m} / \mathrm{s}^{2}\right) /\left(\mathrm{m} / \mathrm{s}^{2}\right)\right)$ & 2.0 & 5.4 & 3.0 & 3.6 & 1.7 \\
\hline
\end{tabular}

In the experiment described in the previous section, Subject A who was relaxed by masking and two subjects who were stressed by masking were selected. It is confirmed in the same table that there is almost no difference in the vibration frequency at which the transfer function reaches the highest value in each part of the human body. The difference in ride feeling sensation that can be evaluated by biological information is not the physical vibration characteristic of the human body of each subject, and psychological conditions and other causes are considered to be significant.

\section{Conclusions}

In this study, we focus on masking to reduce the sensitivity of the disturbance vibration, which contributes to a psychologically uncomfortable feeling, to improve ride comfort. We conducted this study for the purpose of designing a ride comfort control system considering physiological and psychological characteristics. Since the acceleration and frequency of vibration are greatly involved in the comfort of the occupant, basic experiments were conducted on the effect of ride comfort improvement by masking. Furthermore, the number of subjects was increased based on the masking control condition in which improvement of riding comfort was observed, and we conducted a demonstration experiment. In this thesis, we clarified the following: 
(1) $5 \mathrm{~Hz}$ sinusoidal vibration against superimposing 3 and $10 \mathrm{~Hz}$ sinusoidal vibrations with twice the acceleration amplitude by masking results in greater ride comfort than with $5 \mathrm{~Hz}$ sinusoidal vibrations which are susceptible to vibration. This was confirmed by the psychological state evaluation index LF/HF obtained from the ECG.

(2) Based on the above section, the effect of masking by sinusoidal vibrations of 3 and $10 \mathrm{~Hz}$ with twice the acceleration amplitude in twelve subjects was evaluated from the vibration test, and it was confirmed that the effect of masking varied by subject.

(3) To confirm the physical difference between subjects with different effects of improving riding comfort by masking, the vibration transmission rate of each part of the human body was evaluated from the vibration experiment, but no clear difference was confirmed.

Although the results obtained from the above investigation are limited, it was possible to confirm the effect of improving the ride comfort by masking. However, it was revealed that there was a difference in the effect from a psychological point of view, even among subjects with little physical response. Therefore, in order to perform vibration control by masking, it is necessary to select the vibration by sufficiently considering the psychological characteristics of the participant against the vibration. Conversely, vibration with various acceleration amplitudes and frequency bands is considered to be disturbance. In addition, conditions such as acceleration amplitude, displacement amplitude, phase, and frequency characteristics are assumed for the vibration to be superimposed. Furthermore, the psychological state changes from moment to moment, and depending on the psychological state, it is assumed that its effect will change even when the same vibration control is applied. Therefore, in future work, we will systematically summarize the psychological characteristics of passengers and the psychological response by masking control and aim to construct a system that can apply masking control that matches the participant's condition.

Author Contributions: K.I., T.N. and H.K. wrote the paper; A.E. and R.M. conducted the experiments; A.E. contributed through analyzing the data; T.N. and H.K. conceived experiments.

Funding: This research received no external funding.

Conflicts of Interest: The authors declare no conflict of interest.

\section{References}

1. Suzuki, H.; Shiroto, H.; Omino, K. Identification of factors that affect the in-car comfort of a train. J. Rail Rapid Transit 1997, 11, 31.

2. Kitahara, T. Problems in quantitatively evaluating vibration comfort. J. Auto Eng. Jpn. 1978, 32, 667-674.

3. Zhou, Y.; Chen, S. Vehicle ride comfort analysis with whole-body vibration on long-span bridges subjected to crosswind. J. Wind Eng. Ind. Aerodyn. 2016, 155, 126-140. [CrossRef]

4. Smith, D.R.; Andrews, D.M.; Wawrow, P.T. Development and evaluation of the Automotive Seating Discomfort Questionnaire (ASDQ). Int. J. Ind. Ergon. 2006, 36, 141-149. [CrossRef]

5. Mizuno, Y.; Yokoyama, K.; Okada, A.; Hayano, J.; Takada, K. Comparison of bioburden degree in motorcycle/four-wheeled vehicle long distance operation by electrocardiogram R-R interval. Jpn. J. Med. Elec. Biol. Eng. 1998, 36, 87-93.

6. Oshinoya, Y.; Arai, H.; Ishibashi, K. Experimental study on active seat suspension for a small vehicle. Int. J. Appl. Electromagn. Mech. 2004, 19, 437-443.

7. Kato, H.; Hasegawa, S.; Oshinoya, Y. Active Control of Ultra-compact Vehicle Seat. J. Magn. Soc. Jpn. 2013, 37, 95-101. [CrossRef]

8. Kato, H.; Endo, A.; Mashino, M.; Narita, T. Ride Comfort Control System for Ultra-Compact EV by Estimation State of the Driver (Experimental Consideration on Driver's HRV by Driving Operation). In Proceedings of the International Conference on Electrical Engineering, Okimawa, Japan, 3 July 2016.

9. Kato, H.; Ishida, M.; Mashino, M.; Narita, T. Proposal of ride comfort control system by psychological state estimation of the driver. Bull. JSME 2015, 81, 15-00356. [CrossRef] 
10. Kato, H.; Oshinoya, Y.; Hasegawa, S.; Kasuya, H. Ride comfort Evaluation of Active Seat Suspension for Small Vehicles Using Psychology and Physiology-Fundamental Consideration by Analysis Heart Rate Fluctuation and Salivary Amylase Activity. Proc. Sch. Eng. Tokai Univ. 2011, 36, 29-34.

11. Kobori, T.; Kajikawa, Y. Ergonomic Evaluation Methods for Bridge Vibrations. J. Jpn. Soc. Civ. Eng. 1974, 230, 23-31. [CrossRef]

12. Mansfield, N.J.; Griffin, M.J. Effect of posture and vibration magnitude on apparent mass and pelvis rotation during exposure to whole-body vertical vibration. J. Sound Vib. 2002, 253, 93-107. [CrossRef]

13. International Organization for Standardization. Guide for the Evaluation of Human Exposure to Whole-Body Vibration; ISO 2631; ISO: Geneva, Switzerland, 1978.

14. Janeway, R.N. Human Vibration Tolerance Criteria and Application to Ride Evaluation 750166; SAE Technical Paper; SAE International: Warrendale, PA, USA; Troy, MI, USA, 1975.

15. Takei, K.; Ishiguro, M. Evaluation of Ride Comfort on the Basis of Subjective Judgement. RED Rev. Toyota CRDL 1995, 30, 47-56.

16. Yasunao, M.; Griffin, M.J. A Study on Dynamic Response Characteristics of Human Body upon Vertical Vibration Exposure. Jpn. Soc. Civ. Eng. 2002, 703, 185-201.

(C) 2018 by the authors. Licensee MDPI, Basel, Switzerland. This article is an open access article distributed under the terms and conditions of the Creative Commons Attribution (CC BY) license (http://creativecommons.org/licenses/by/4.0/). 